\title{
1 First in situ tests of a new electrostatic resistivity meter
}

2 Sébastien Flageul ${ }^{1}$, Michel Dabas ${ }^{2}$, Julien Thiesson ${ }^{1}$, Fayçal Rejiba ${ }^{1} \&$ Alain Tabbagh ${ }^{1}$

3

4

5

6

7

8

${ }^{1}$ UMR Sisyphe,UPMC/CNRS, case 105, 4place Jussieu 75252 Paris Cedex05, France

${ }^{2}$ GEOCARTA, 5 rue de la Banque 75002 Paris, France

\section{Abstract}

If field applications of the electrostatic method are limited to roughly the first ten metres due to the necessity of staying in the low induction number domain, the possibilities it opens in urban area surveying, dry hole resistivity logging, non-destructive testing and laboratory studies of the complex resistivity justify the design of a new multi-frequency resistivity meter presenting a very low input capacitance and a high phase sensitivity. After a first series of sample measurements in laboratory, the new resistivity meter was tested in two different field contexts: the mapping of building remains in a Gallo-roman archaeological site under a flat meadow, and the assessment of the anthropogenic layers thickness in a town. The first test allowed a direct comparison with previous galvanic resistivity measurements and proved a very good agreement between both in magnitude and spatial distribution of electrical resistivity. The second test established its reliable measuring abilities in a disturbed environment.

Key words: electrical resistivity, electrostatic method, non galvanic capacitive contacts, archaeological and engineering applications

\section{Introduction}

Electrical resistivity is a relevant parameter for near surface investigations as it exhibits a very large range of variation and is highly dependent upon clay and water content 
within earth materials. Since nearly over one century, a wide set of techniques were thus developed for performing its measurement, among which the mostly used galvanic measurements with a four electrode array can be considered as the reference technique. Unfortunately galvanic contact is not possible over all surfaces. If electromagnetic induction methods have also been applied, their ability to detect resistive targets remains limited. Moreover, measurements are sensitive to the presence of metallic objects which limits their use in difficult environments, like towns or waste disposals for example. E.M. induction methods cannot also be used at laboratory scale for resistivity and permittivity determinations. In electrostatic method, measurements are achieved without any galvanic contact by electrostatic influence only (Grard and Tabbagh 1991, Tabbagh et al. 1993, Kuras et al. 2006). This opens the possibility to survey over insulating surfaces like tarmac, pebble stones, concrete slabs, etc. and in magnetically and/or electromagnetically noisy environments.

The poles that are used both for current injection and voltage measurements correspond to simple metallic pieces like for example a sheet of copper insulated with rubber. The surface of the poles determines the capacitance and thus the impedance of the system. For example a $20 \mathrm{~cm} \times 20 \mathrm{~cm}$ metallic sheet has a $9 \mathrm{pF}$ capacitance in free air and $18 \mathrm{pF}$ when put on the ground. The corresponding impedances being $9 \mathrm{M} \Omega$ at $1 \mathrm{kHz}$ and $90 \mathrm{k} \Omega$ at $100 \mathrm{kHz}$, it is difficult to use frequencies lower than several $\mathrm{kHz}$. Both this frequency constraint and the application of the low induction number condition (Benderitter et al. 1994) limit the size of the arrays and thus the depth of investigation to roughly the first ten metres.

Despite this depth limitation, its applications cover a large range from soundings in both field and urban contexts (Benderitter et al. 1994, Tabbagh and Panissod 2000), to archaeological and pedological surveys (Panissod et al. 1998, Dabas et al. 2000), to architectonic material non-destructive testing (Féchant et al. 1997, Souffaché et al. 2010) and to resistivity logging in dry holes (Leroux 2000, Guérin et al. 2002, Mwenifumbo et al. 2009). 
Only very few instruments have been developed yet both by laboratories and manufacturers (Shima et al. 1996, Kuras et al. 2007) but the use of this technique is increasing in engineering geophysics.

Considering both the present abilities of the method and its potential developments, we choose to improve the instrument specifications and design in order to increase measurement reliability in noisy environments and for simultaneous measurements of both resistivity and permittivity independent of geometrical scale. The new meter specifications are described hereafter before presenting the results of two different case terrain applications.

\section{Instrument specifications and design}

The first choice to be achieved for the definition of a new resistivity meter is the choice of the frequency range: It results from the balance between induction number and capacitances of the poles, $100 \mathrm{kHz}$ corresponding to a suitable upper limit. The second choice is to reach as precise as possible phase measurements of the voltage by reference to the injected current. This option not only corresponds to the logical improvement of presently used apparatus but also to ability of measuring the permittivity in the low frequency range (that may comprise both Maxwell-Wagner membrane polarization and water molecule rotation (Tabbagh et al. 2009)); and thus exploring new paths for a series of environmental applications. As a logical consequence of this second requirement, it is interesting to extend the frequency range down to few milli $\mathrm{Hz}(\mathrm{mHz})$ to facilitate a full investigation of the polarisation characteristics on laboratory samples with the same meter and galvanic contacts (Okay 2011). To be able to use poles of limited surface $\left(4 \mathrm{x} 4 \mathrm{~cm}^{2}\right.$ for instance) in small geometry arrays, the input capacitance down the pole itself should be as low as possible, less than $1 \mathrm{pF}$. The voltage reference was managed in order to avoid the addition of a grounding pole. 
This instrument is called SECR-1 (Spectral Electrostatic Complex Resistivity-meter); its electronics bloc diagram is presented in Figure 1a. The specifications of the meter are thus: frequency range $2 \mathrm{mHz}-100 \mathrm{kHz}$, injection voltage between 40 and $400 \mathrm{~V}$ peak to peak (maximum current $44 \mathrm{~mA}$ peak to peak), input capacitance $<1 \mathrm{pF}$ and input electrical resistance $>30 \mathrm{M} \Omega$ down each voltage pole, precision of the phase detection: 1 milliradians, total measurement dynamic range: 18 bits with a LSB (least significant bit) at $19 \mu \mathrm{V}$.

One of the original improvements, shown in Figure 1b, is the use of a coaxial link with shield between each voltage pole and the first amplifier which is maintained at the same voltage as the one of the pole.

\section{First Test on the Gallo-Roman archaeological site at Vieil-Evreux (Eure, France)}

The Gisacum religious centre is located $7 \mathrm{~km}$ east of the capital city of Aulerques Eburovices (now Evreux in Normandy). There, inside a great hexagonal sacred polygon covering 230 ha, stand a series of public buildings and temples, the dwelling and craft activities being situated outside the polygon (Guyard and Lepert 1999). This site is located over a great plateau where the superficial layer corresponds to flint clay. Above this clay, of $17 \Omega . m$ resistivity, the archaeological remains have a variable thickness and may overpass $100 \Omega . m$ in resistivity. None of the remains are today visible and only the thermal baths building has been excavated. The electrical map of the area is presented in Figure 2 where all substructions are clearly shown as resistive anomalies in white: walls of the Gallo-roman temple (fanum), walls around the thermal complex (peribola), dwelling houses to the West delimited by roads (via), aqueducts to the South bringing water to the thermal complex and to the temple of water (nymphea) (see Dabas et al. 2005 for a complete explanation of archaeological features). 
The test took place at the northern border of the fanum (outlined blue rectangle in

Figure 2) where the thickness of the archaeological 1 layer remains is around $90 \mathrm{~cm}$. The test compares the results obtained using a three depths multipole array called ARPC (Automatic Resistivity Profiling), presented in Figure 3(a), to those obtained with the two depths electrostatic MPG ('Multi Pôle Général') array, Figure 3(b).

The ARPC is of common use for pedological and archaeological applications (Dabas, 2009) it weighs $400 \mathrm{~kg}$ and has 8 spike wheels. The MPG was designed for manually towed urban prospection (Dabas et al. 2000), it is made of fiber glass tubes and the poles are brass plates encapsulated in a double sheet of rubber to avoid any galvanic contact, it weighs $40 \mathrm{~kg}$. Both arrays were pulled with a quad-bike over a grass cover and the measurement location was obtained using a combination of dGPS system and a radar Doppler system that allows checking the distance along the profile.

The test was performed in the field in three phases:

All these Dataset were compared to the standard apparent electrical resistivity formerly Survey1: Continuous measurement of apparent electrical resistivity using SECR-1 resistivity-meter and standard galvanic electrodes of the ARPC system towed by a Quad bike. Data obtained will be further referred as Dataset1, Survey2: Continuous measurement of apparent electrical resistivity using SECR-1 resistivity-meter and MPG capacitive poles manually pulled over the surface by the operator. Data obtained will be further referred as Dataset2, Survey3: Continuous measurement of apparent electrical resistivity using SECR-1 resistivity-meter and MPG capacitive poles towed continuously by the Quad bike. Data obtained will be further referred as Dataset3,

obtained over the same area either by the handheld RM15 (Geoscan Research ltd) resistivitymeter (operating frequency $137 \mathrm{~Hz}$ ) or by the ARPC continuous electrical profiling system 
with its dedicated AFM05 resistivity-meter. AFM05 is a three channel regulated current resistivity-meter, operating at $225 \mathrm{~Hz}$, and is optimized for continuous measurements with fast settling time and for high tolerance in contact resistance and asymmetry in the impedance of the poles.

Survey1: The first test was done in order to check if the SECR-1 reacts as a 'standard' resistivity-meter when pulled continuously. Mapping with the SECR-1 was repeated at two different frequencies $122 \mathrm{~Hz}$ and $1 \mathrm{kHz}$. An area of $3700 \mathrm{~m}^{2}$ was surveyed with parallel E-W profiles running in zigzag. A mean inter-profile offset of $1.0 \mathrm{~m}$ was adopted using a guided real-time navigation system integrated in the process of data acquisition in the field computer and with $0.19 \mathrm{~m}$ mean inline measurement step. With an average velocity of $1.9 \mathrm{~ms}^{-1}, 38000$ measurements were acquired in less than one hour.

SECR-1 measurements consist of 6 available data: the real and imaginary parts of injection current, $\mathrm{I}_{\mathrm{ph}}$ and $\mathrm{I}_{\mathrm{qu}}$, and the phase and quadrature components of the voltages for each channel: $V_{1 p h}, V_{1 q u}, V_{2 p h}, V_{2 q u}$ From these data, the initial phase reference being arbitrary, it is possible to plot the real and imaginary part of the apparent electrical resistivity knowing the geometrical factors $(\mathrm{K} 1=4.6 \mathrm{~m}$ for channel ARP1 and $\mathrm{K} 2=10 \mathrm{~m}$ for channel ARP2), one has for example: $R\left(\rho_{a 1}\right)=K 1 \frac{V_{1 p h} I_{p h}+V_{1 q u} I_{q u}}{I_{p h}^{2}+I_{q u}^{2}}$ for the real part and $\operatorname{Im}\left(\rho_{a 1}\right)=K 1 \frac{V_{1 q u} I_{p h}-V_{1 p h} I_{q u}}{I_{p h}^{2}+I_{q u}^{2}}$ for the imaginary part.

However due to the resistivity and frequency ranges and in view of the comparison to former acquired galvanic resistivity data, we here only consider the in-phase (real resistivity) measurements. In order to get a map, data are then re-sampled along the profile at each dGPS position and a $2 \mathrm{D}$ interpolation is performed (square mesh $0.25 \mathrm{~m} \times 0.25 \mathrm{~m}$ ). The data (dataset1) corresponding to channel ARP1 and a frequency of $1 \mathrm{kHz}$ is shown in colours in Figure 4. Despite some slight positioning problems due to dGPS availability (a herringbone 
effect is seen for some lines of acquisition especially in the northern part), the spatial definition of anomalies is very good. Dataset1 was compared to data obtained manually with RM15 resistivity-meter (in grey in Figure 4) in 1999 (manual acquisition in pole-pole configuration with $\mathrm{a}=0.5 \mathrm{~m}$, in-line and between line spacing of $0,5 \mathrm{~m})$. It is not possible to compare the absolute values between these two Dataset because of the different array geometries used and the time between surveys. Nevertheless the graphical superposition in a GIS of the two maps, show the clear correspondence and superposition of all resistive anomalies linked to the roman walls. After this first trial, we considered that the new SECR-1 can be used as a standard galvanic resistivity-meter.

We have then performed on the same day an acquisition of electrical resistivities using the AFM05 and channel ARP1 and ARP2 configuration over a small part (map not shown). Since, the AFM05 is calibrated with absolute resistance, it is possible to compare the resistivities each other. The results are summarised in Table 1 using all raw data (area of $43 \mathrm{x}$ $8 \mathrm{~m}^{2}$, raw data without re-sampling on a grid). Considering that the position of each of the points is not identical between these two datasets - even if the area is the same-, the correspondence in the absolute values is very good, in particular for channel ARP2 where the apparent resistivities integrate a bigger volume. After these two tests, we conclude that the SECR-1 can be used as a standard calibrated galvanic resistivity-meter.

Survey2: The second test was done in order to check the response of the SECR-1 when using electrostatic poles (MPG) in a simple situation where the system is pulled manually by the operator (data acquisition in this situation is triggered by a simple time interval). Due to the weight of the system, the area which was surveyed was limited $(400 \mathrm{~m} 2)$ and was covered by 8 parallel profiles $1 \mathrm{~m}$ apart. Distance between points is around $8 \mathrm{~cm}$ along the profiles. The derived Dataset 2 results in the map shown in figure 5 both for channels MPG1 and MPG 2. All features which were previously found using either manual 
175 (RM15) or continuously-towed system (ARPC) were mapped again and in great details (see 176 Fig. 2 for example). This is the first time (compared to other trials with commercially 177 available electrostatic systems) that we were able to map so clearly such structures using 178 electrostatic poles.

We have then performed the comparison between DS2 and resistivities obtained galvanically with AFM05 (see Survey 1) and using the same electrodes configuration because channel ARP2 is nearly the same geometrical configuration as channel MPG1 that is a $1 \mathrm{~m}$ square array (channel ARP1 cannot be compared to any of the MPG channel). The results of this statistical analysis are shown in Table 2. Considering also the results of Survey1, it is clear that apparent resistivities measured by electrostatic poles and with the SECR-1 are identical with those measured galvanically. SECR-1 can now be considered as a calibrated electrostatic resistivity-meter.

Survey3: The final step was to prove that the system can also be used dynamically by pulling it on the ground surface and triggering the data acquisition by measuring the distance over ground surface (Doppler radar). The whole area (3350m2) was surveyed using SECR-1 and the MPG configuration towed by the Quad bike in 1.15 hour (average speed:1.4 $\mathrm{ms}^{-1} ; 15$ cm inline steps, $1.0 \mathrm{~m}$ inter-profile offset, input voltage set at $196.5 \mathrm{~V}$ and frequency set at 31 $\mathrm{kHz}$ ). The resulting Dataset3 was gridded to obtain the map plotted in Figure 6a superimposed to an electrical map obtained previously in 2006 using the ARPC system and a RTK (Real Time Kinematics) post-processing (Dabas and Favard 2004). This quality of the derived map proves that this system can be used to produce maps at a quality level equivalent to that obtained with the ARPC systems even if the towing speed is still low. At present, the limitation in the towing speed is due to the mechanical strength of the MPG system which was not designed for this purpose. 
Second test: Thickness of the different natural and anthropogenic sediments in urban context

One of the difficulties we have to face in urban environment is to identify the nature of the subsoil in the presence of high resistivity changes corresponding to the pavement itself (also to the foundations of the pavement) and in the presence of a great range of utility pipes that carry water, gas, telephone links, etc. These generate the high GPR reflections that hide the deeper structure in the ground. Plurimetric electrostatic arrays are able to deliver correct response even in presence of such features (Tabbagh and Panissod 2000), thus the new resistivity meter was used within the frame of a pilot test undertaken in the city of Tours (Indre et Loire, France).

Tours is a Gallo-Roman city built in the interfluves between two rivers, the Loire and its tributary, the Cher. As a reconnaissance step of a project of new tramway transportation system, we were asked to recognize the electrical resistivity of the first seven metres to assess the nature of both natural and anthropogenic sediments. To achieve this goal, we used electrostatic arrays that were pulled in the streets (Fig.7) during the night in order to limit the traffic disturbances. Wenner $\beta$ configuration with four different inter-pole distances: $3 \mathrm{~m}, 5 \mathrm{~m}$; $7 \mathrm{~m}$ and $10 \mathrm{~m}$ was applied with a $1 \mathrm{~m}$ measurement step. This allowed drawing apparent resistivity pseudo-sections which can be compared with other sources of information. For example the results obtained in one of the streets (Charles Gille) are presented in Figure 8. The eastern part of this street dates back to the modern epoch and is present in a $19^{\text {th }}$ century city plan, whereas its western part was gone through former constructions at the beginning of the $20^{\text {th }}$ century. Except for the remains of a huge building between 220 and $240 \mathrm{~m}$, the eastern part is quite conductive which can be interpreted by the absence of underground constructions, while the western part exhibits higher resistivity values for the top layers , extending to few metres depth, in likely relation with the preceding building cellars or 
225 foundations. A 1D three layer interpretation model allows an approximate location of the depth and thickness of the conductive layer corresponding to the natural alluviums and of the

227

228 anthropogenic remains above.

\section{Conclusions}

The two field tests presented here allowed to first compare the electrical resistivity magnitude and spatial distribution obtained by SECR-1 to the ones previously measured using classical galvanic techniques. The agreement between measurements acquired with the new resistivity meter and galvanic electrodes are very precise, as is the agreement between low frequency measurements using electrostatic poles (capacitive) and galvanic electrodes. This confirms the identity of results using both methods for shallow depth applications. The second test was undertaken in a disturbed urban environment where both electrical noise and underground net of pipes and cables may contaminate the signal. The electrical pseudosection is in good agreement with what is known about the city street modifications at the beginning of the $20^{\text {th }}$ century. In these experiments the size of the electrostatic poles, the aimed depths of investigation (and thus the injected current intensities), the nature of ground surfaces are sufficiently different to establish the reliability of the measurements using the new resistivity meter which fulfils the requirements corresponding to the diverse applications of the electrostatic method in near surface geophysics. 
Benderitter Y., Jolivet A., Mounir A. and Tabbagh A. 1994. Application of the electrostatic quadripole to sounding in the hectometric range of depth. Journal of Applied Geophysics 31, $1-6$.

Dabas M., Camerlynck C. and Freixas i Camps P. 2000. Simultaneous use of electrostatic quadrupole and GPR in urban context: Investigation of the basement of the Cathedral of Girona (Catalunya, Spain), Geophysics 65, 526-532; doi:10.1190/1.1444747

Dabas M. and Favard A. 2004. Fast imaging of a Romano-Celtic temple with a decimetric resolution, 1ha in 2hours? $10^{\text {th }}$ European Meeting of Environmental and Engineering Geophysics, September 6 to 9, Utrecht.

Dabas M., Guyard L. and Lepert T. 2005. Gisacum revisité : croisement géophysique et archéologie. In " Géophysique et archéologie », Dossiers de l'Archéologie 308, 52-61.

Dabas M. 2009. Theory and practice of the new fast electrical imaging system ARPC. In: Press, 105-126. mécanique de pierres de taille in-situ. Revue d'Archéométrie 21, 45-53. Grard R. and Tabbagh A. 1991. A mobile four-electrode array and its application to the electrical survey of planetary grounds at shallow depths. J.G.R 96, B-3, 4117-4123.

Guérin R., Bégassat P., Benderitter Y., David J., Tabbagh A and Thiry M. 2002. Electrical resistivity measurements by electromagnetic slingram mapping, electrical $2 \mathrm{D}$ and $3 \mathrm{D}$ imaging, and electrostatic logging: a tool for studying an old waste landfill. 8th annual meeting of the Environmental and Engineering Geophysical Society - European Section, Aveiro (Portugal), 08-12/09/2002. 
Guyard, L. and Lepert T. 1999. Le Vieil- Evreux, ville sanctuaire gallo-romaine, Archeologia 359, 20-29.

Kuras O., Beamish D., Meldrum P. I., and Ogilvy R. D., 2006, Fundamentals of capacitive resistivity technique. Geophysics $\mathbf{7 1 - 3 , 1 3 5 - 1 5 2 . ~}$

Kuras O., Meldrum P. I., Beamish D., Ogilvy R. D. and Lala D. 2007. Capacitive Resistivity imaging with towed arrays, Journal of Environmental and Engineering Geophysics 12-3, 267279.

Leroux V. 2000. Utilisation d'électrodes capacitives pour la prospection électrique en forage, Thèse, Université de Rennes I, 210 pages.

Mwenifumbo C. J., Barrash W., and Knoll M. D. 2009. Capacitive conductivity logging and electrical stratigraphy in a high-resitivity aquifer, Boise Hydrogeophysical Research Site. Geophysics 74-3, E125-E133.

Okay G. 2011. Caractérisation des hétérogénéités texturales et hydriques des géomatériaux argileux par la méthode de Polarisation Provoquée: Application à la station expérimentale de Tournemire. Thèse Université Pierre et marie Curie, 342 pages.

Panissod C., Dabas M., Hesse A., Jolivet A., Tabbagh J. and Tabbagh A. 1998. Recent developments in shallow electrical and electrostatic prospecting using mobile arrays. Geophysics 63-5, 1542-1550.

Shima H., Sakashita S. and Kobayashi T. 1996. Development of non-contact data acquisition techniques in electrical and electromagnetic explorations. Journal of Applied Geophysics 35, 167-173.

Souffaché B., Cosenza P., Flageul S., Pencole J. P., Seladji S. and Tabbagh A., 2010, Electrostatic multipole for electrical resistivity measurements at decimetric scale., Journal of Applied Geophysics 71-1 :6-12. 
294 Tabbagh A., Cosenza P., Ghorbani A., Guérin R. and Florsch N., 2009, Modelling of 295 Maxwell-Wagner Induced Polarisation Amplitude for Clayey Materials, Journal of Applied 296 geophysics 67-2, 109-113.

297 Tabbagh A., Hesse A. and Grard R. 1993. Determination of electrical properties of the ground 298 shallow depth with an electrostatic quadrupole: field trials on archaeological sites. 299 Geophysical Prospecting 41-4, 579-597.

300 Tabbagh A. and Panissod C. 2000. 1D complete calculation for electrostatic soundings 301 interpretation. Geophysical Prospecting 48-3, 511-520.

302 


\section{Figure captions}

Figure 1: (a) Bloc diagram of the electronics of SECR-1 resistivity-meter, (b) bloc diagram of the measurement channel electronics (DAC means Digital Analogic Converter, ADC means Analogic Digital Converter, HV means High Voltage).

Figure 2: General apparent resistivity map of the western part of Vieil-Evreux Gallo-roman site, obtained with ARP(C) channel 2 at $225 \mathrm{~Hz}$ where the experiment area corresponds to the rectangle in blue

Figure 3: (a) ARP(c) system and array geometry (b) MPG system and array geometry.

Figure 4: Comparison between the apparent resistivity maps acquired using RM15 in grey scale (Top of the figure, pole-pole $50 \mathrm{~cm}$ array configuration) and Dataset1 in colour scale (bottom of the figure, SECR-1 at $1 \mathrm{kHz}$; channel ARP1 configuration), together with the corresponding apparent resistivity histograms, values in $\Omega . m$.

Figure5: Map of Dataset2 in colour scale (SECR-1 at $31 \mathrm{kHz}$; channels MPG1 and MPG2; manual measurements) with apparent resistivity histograms (values in $\Omega . m$ ).

Figure 6: Comparison between the apparent resistivity map acquired using AFM05 in greyscale $(225 \mathrm{~Hz}$; channel ARP2, continuous measurements) and Dataset3 (SECR-1 at $31 \mathrm{kHz}$; channel MPG1, continuous measurements) in colour scale, together with the corresponding apparent resistivity histograms (values in $\Omega . m$ ).

Figure 7: Sliding independent pole array (MPI, Multi-Pôles Indépendants) at the 'nationale' street in Tours (37, France).

Figure 8: (a) Pseudo section of apparent resistivity acquired using the SECR-1 at $15 \mathrm{kHz}$ using $3 \mathrm{~m}, 5 \mathrm{~m}, 7 \mathrm{~m}$ and $10 \mathrm{~m}$ inter-pole distances along 'Charles Gille' street, (b) 1D three layer smoothed interpretation, and corresponding information elements (c) and (d). The natural alluvium corresponds to silty sand, at $120 \mathrm{~m}$ is located the eastern limit of ancient (modern 
328 epoch) constructions, the low resistive zone between 120 and $140 \mathrm{~m}$ can be interpreted as an 329 ancient river arm.

330 


\section{Table captions}

334 Table 1: Dataset1: Statistics between apparent electrical resistivity $(\Omega . \mathrm{m})$ measured with 335 AFM05 (ARPC system, at $225 \mathrm{~Hz}$ ) and SECR-1 resistivity-meter (at $122 \mathrm{~Hz}$ ): (N number of 336 measurements, Q1 first quartile e.g. number below which lies 25\% of the data, Q3 third 337 quartile i.e. number below which lies $75 \%$ of the data).

338

339 Table2: Dataset2: Statistics between apparent resistivity measured with galvanic coupling and 340 apparent resistivity measured with electrostatic (capacitive) coupling. 


\begin{tabular}{|l|c|c|c|c|c|}
\hline Apparent electrical resistivity & $\mathrm{N}$ & $\mathrm{Q} 1$ & Mean & Median & Q3 \\
\hline with AFM05 Channel1 & 5338 & 54.8 & 61.1 & 59.8 & 65.9 \\
\hline with SECR-1 Channel 1 & 5338 & 52.8 & 65.7 & 63.0 & 70.5 \\
\hline with AFM05 Channel 2 & 5244 & 44.8 & 51.7 & 49.4 & 55.9 \\
\hline with SECR-1 Channel 2 & 5372 & 43.6 & 51.4 & 48.5 & 55.3 \\
\hline
\end{tabular}

343

Table 1

344

\begin{tabular}{|l|c|c|c|c|c|}
\hline Apparent electrical resistivity & $\mathrm{N}$ & $\mathrm{Q} 1$ & Mean & Median & Q3 \\
\hline ARPC channel2 & 3134 & 42.8 & 50.8 & 48.2 & 54.4 \\
\hline MGP channel 1 & 3134 & 42.6 & 47.9 & 46.3 & 51.1 \\
\hline
\end{tabular}

345

Table 2 


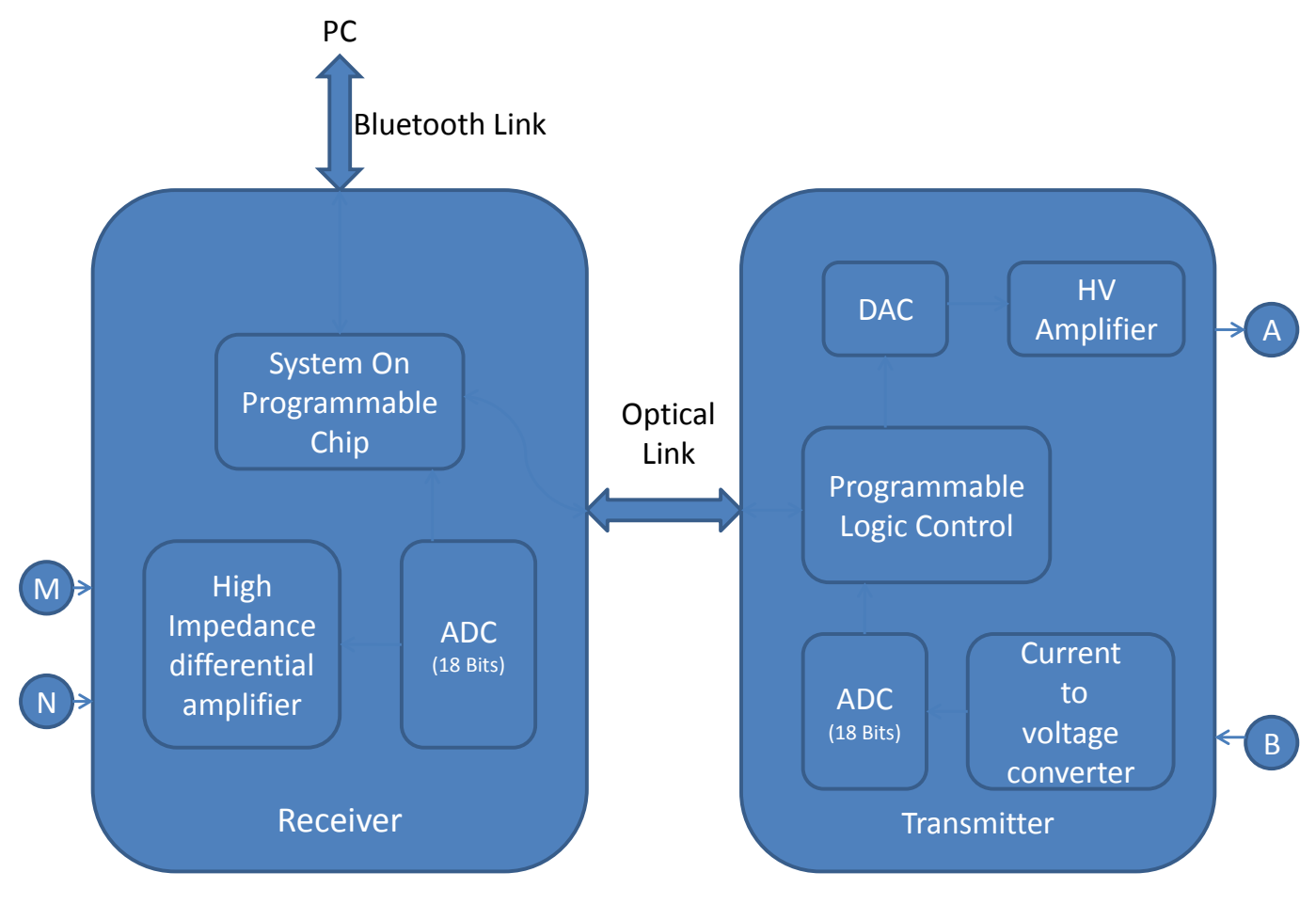

348

Fig: 1(a)

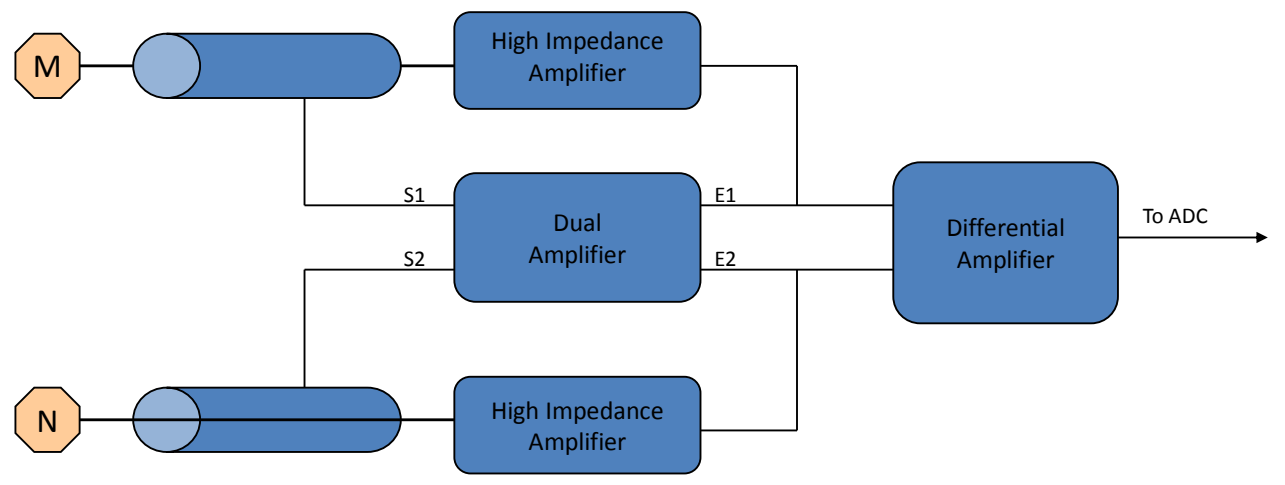




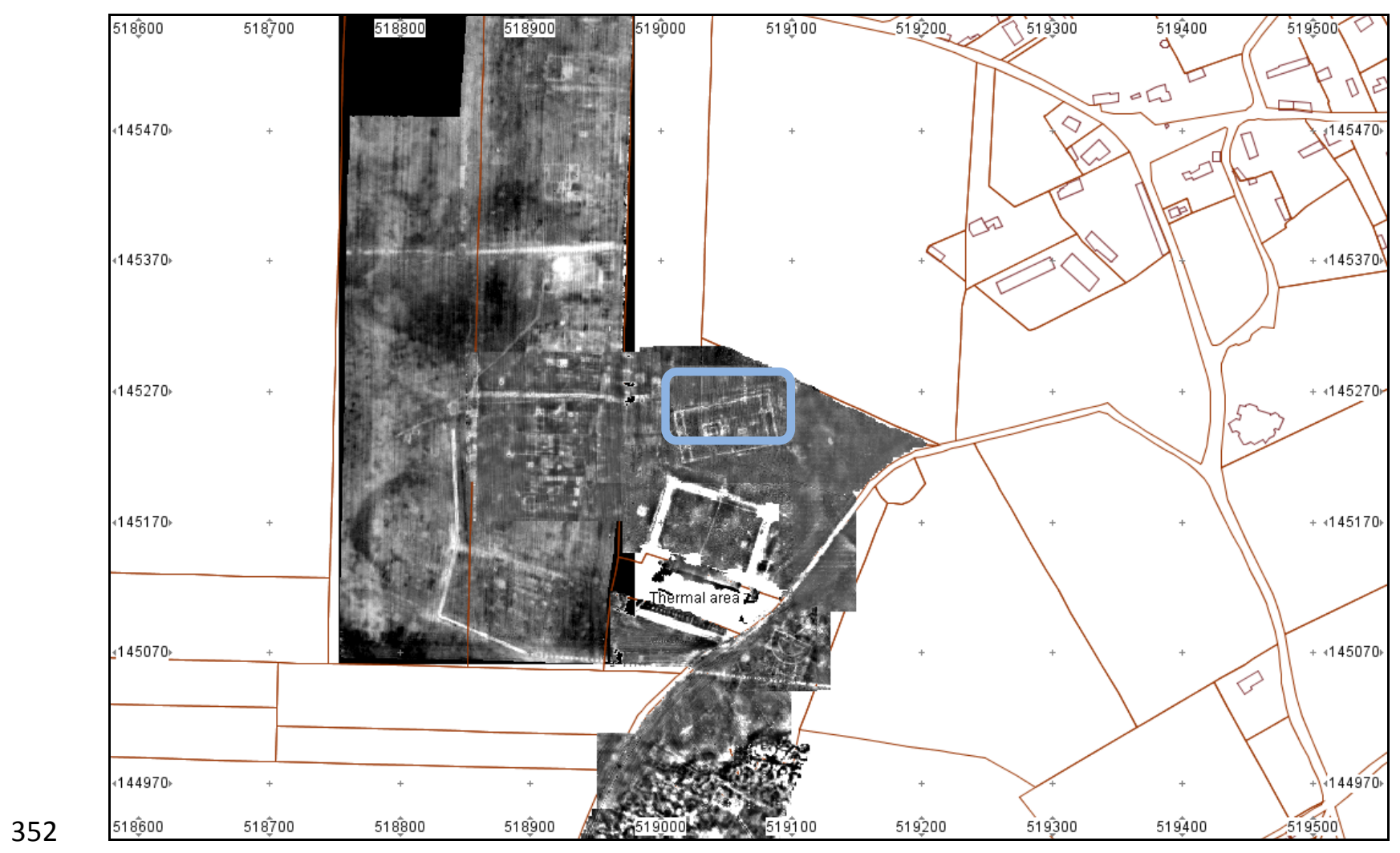

$353 \quad$ Fig 2

354 Fig. 3(a)

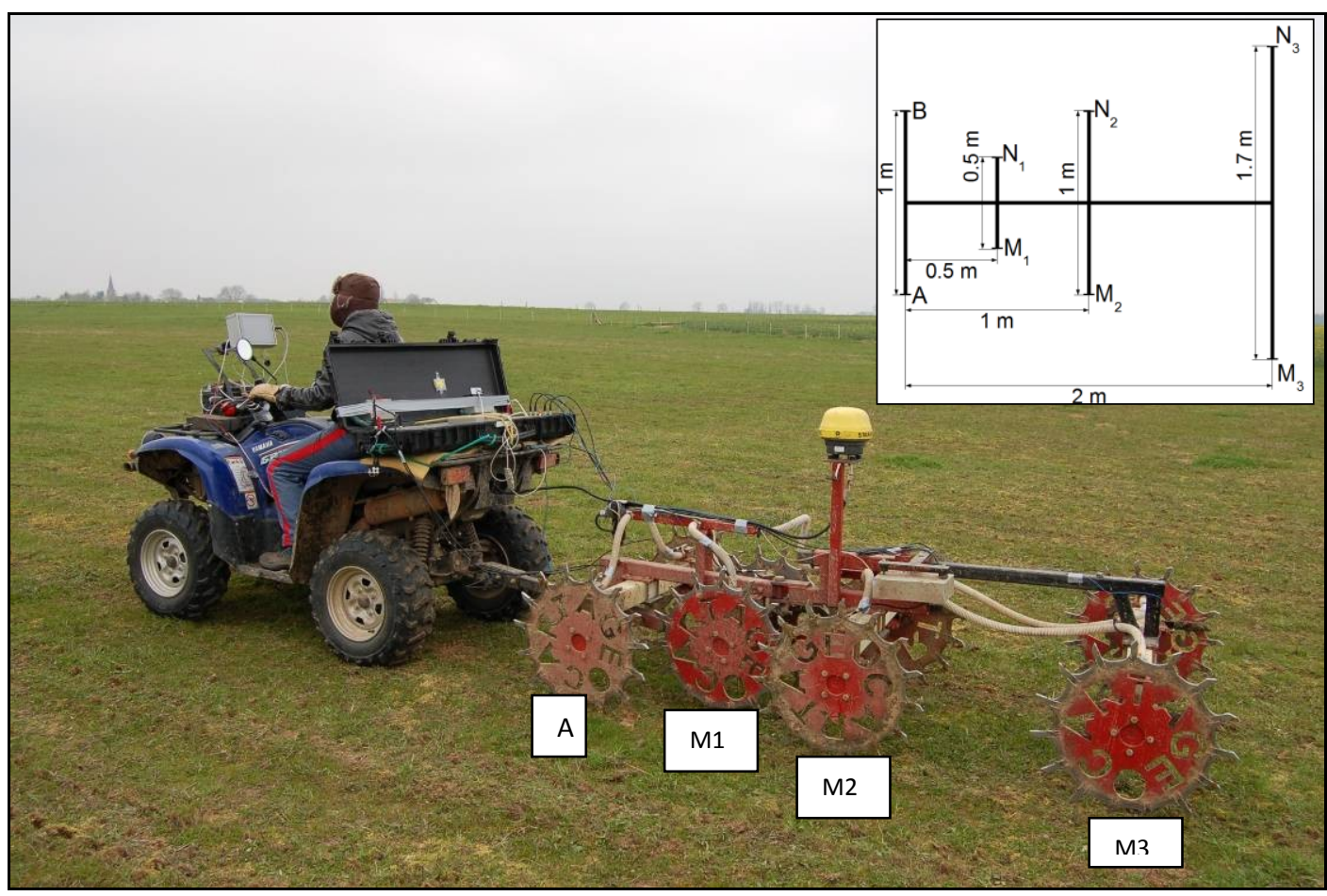


$359 \quad$ Fig3 (b)

360

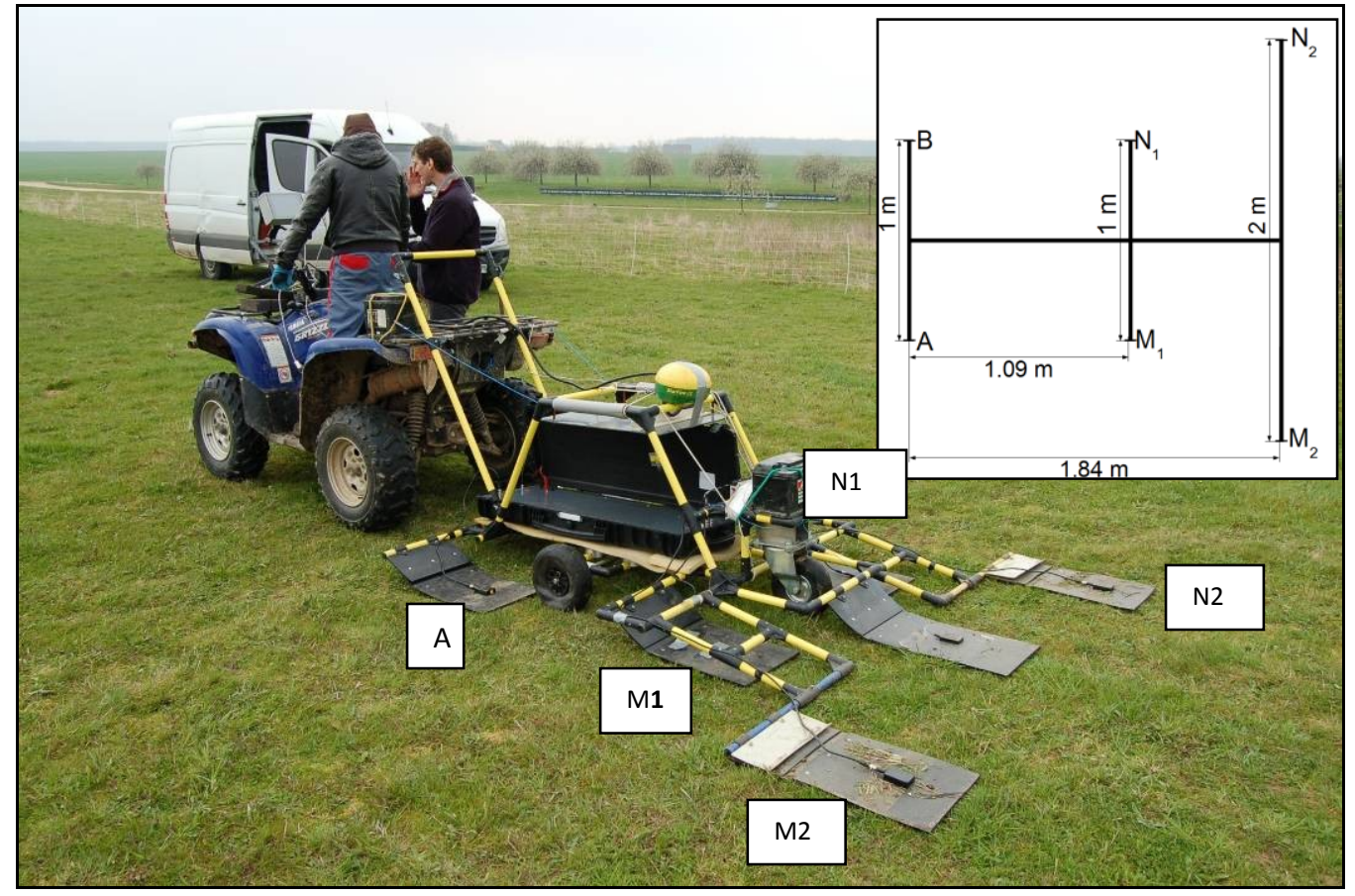

361 


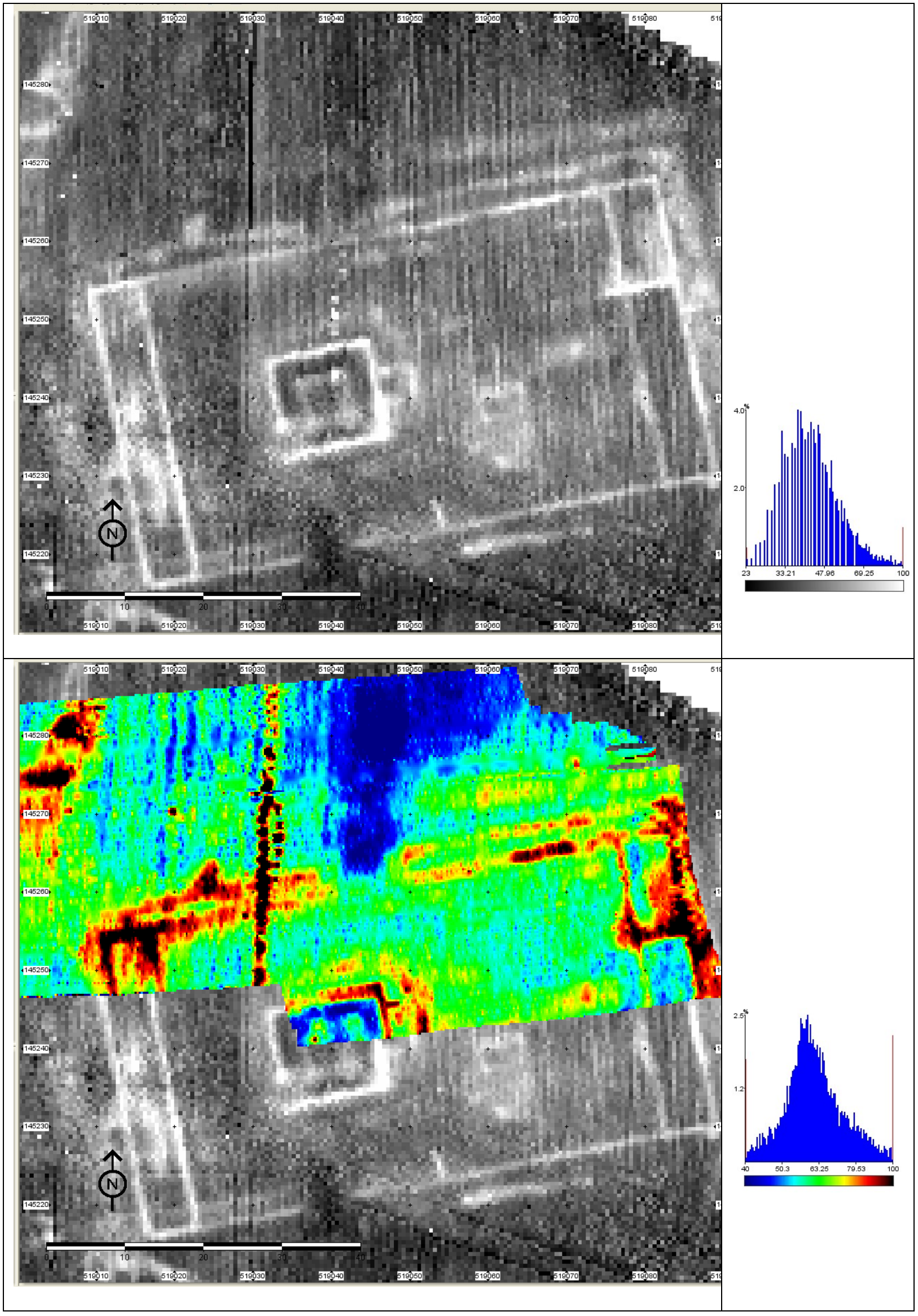


$364 \quad$ Fig 5

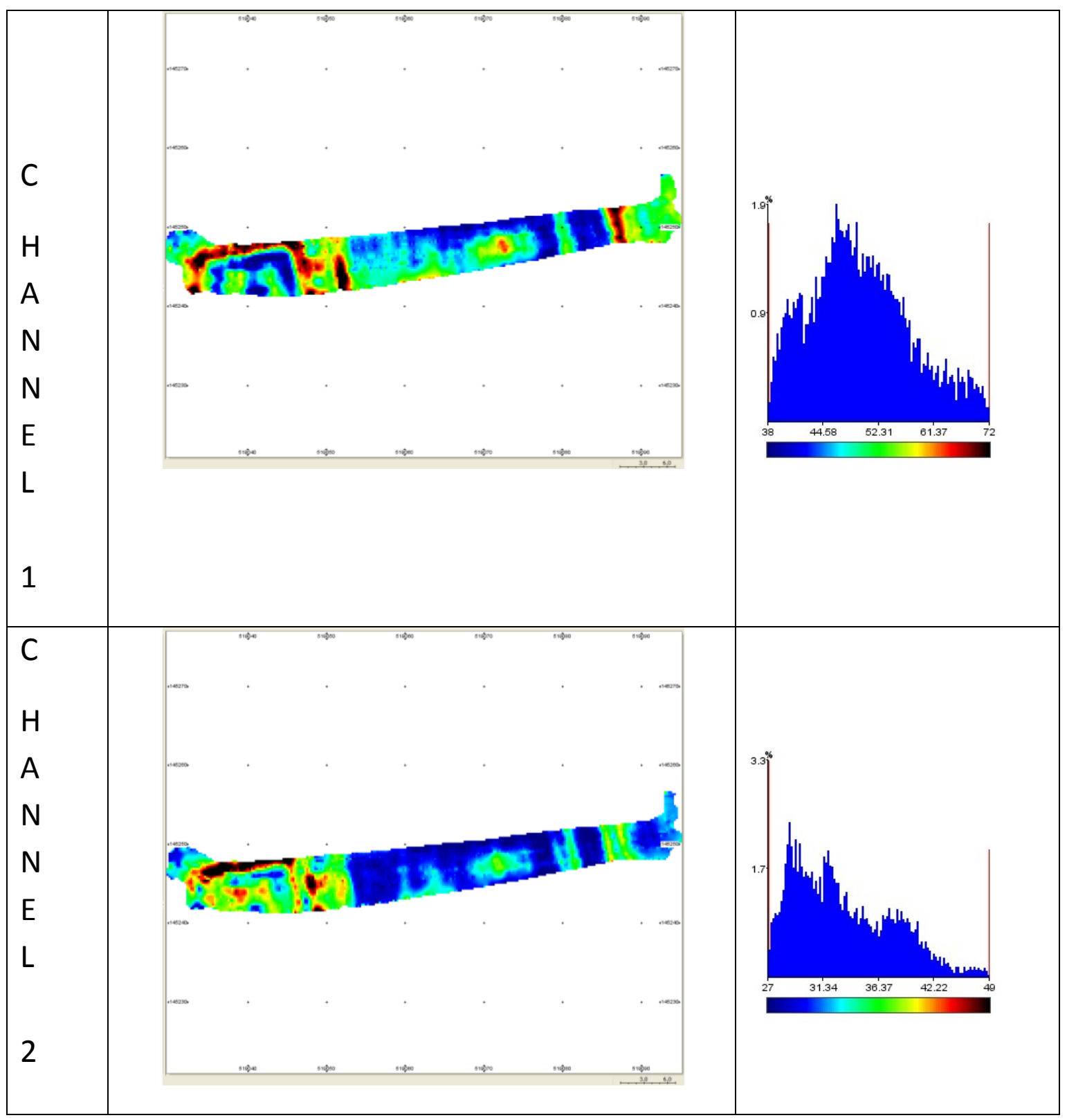

365 
Fig. 6

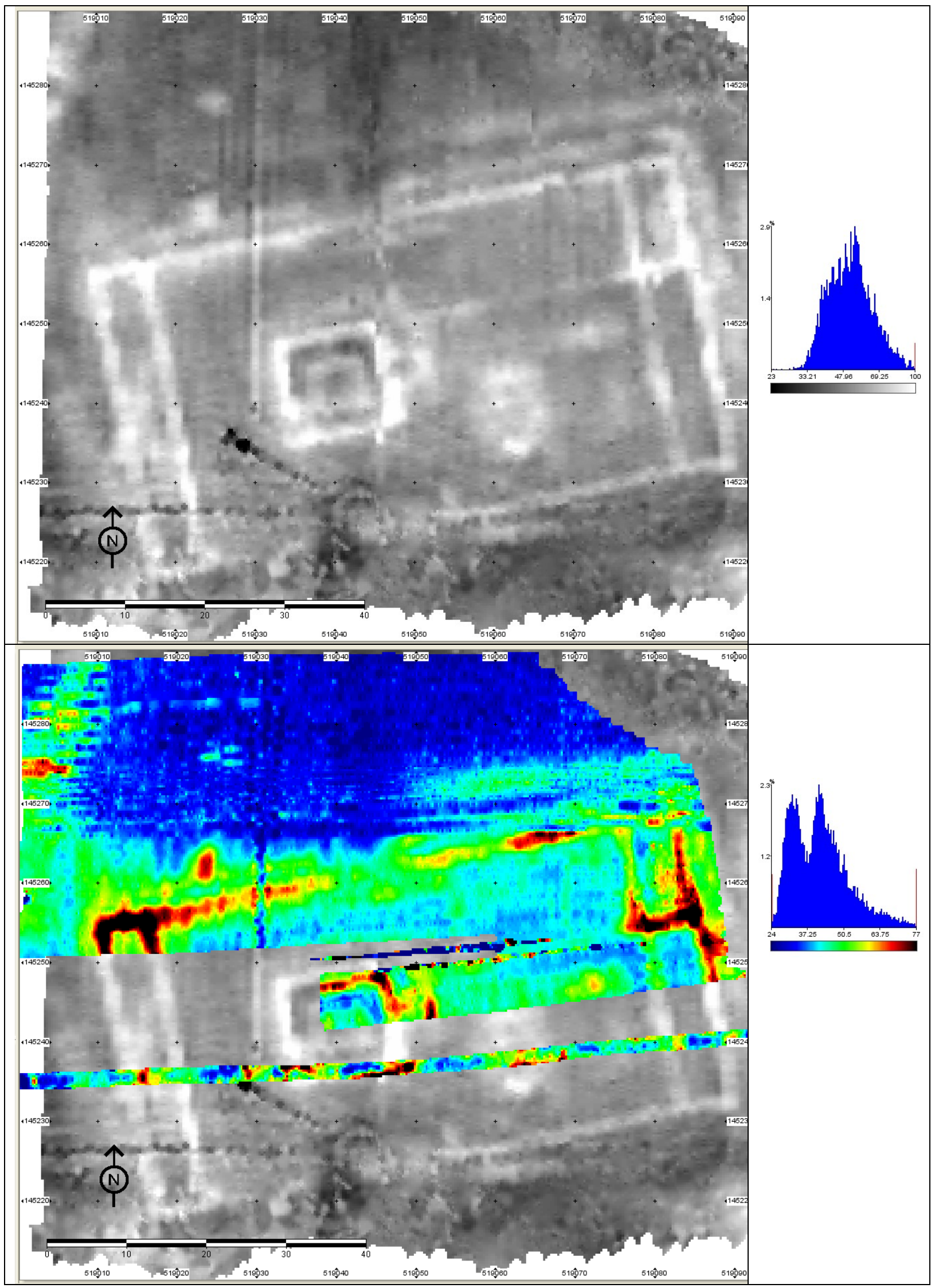


Fig. 7

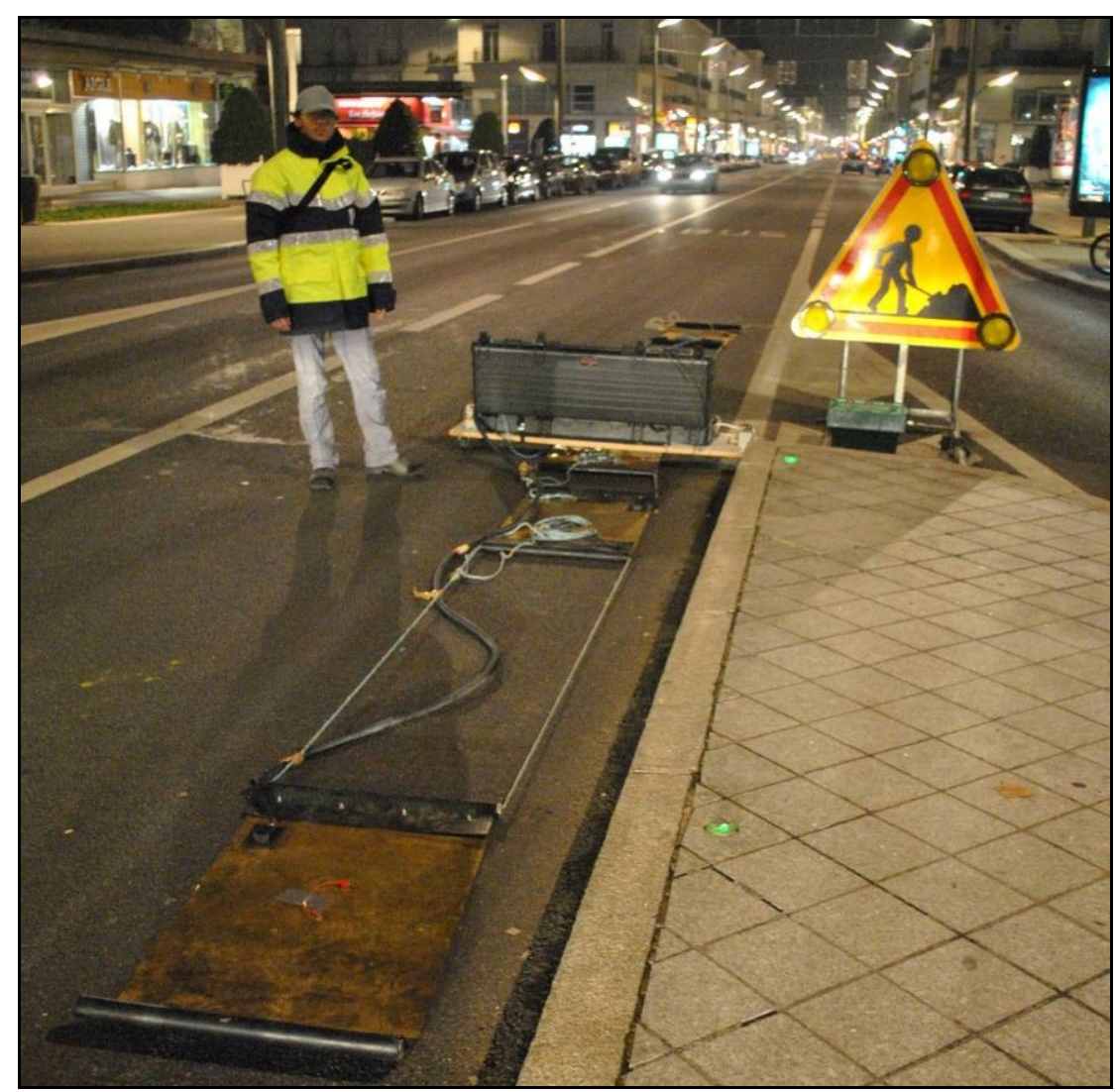

371

372 
$374 \quad$ Fig. 8

$\rho_{\mathrm{a}}(\Omega . \mathrm{m})$

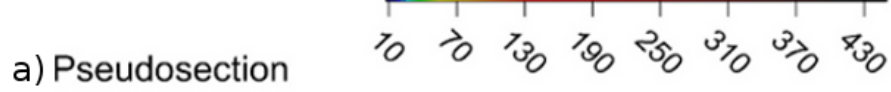

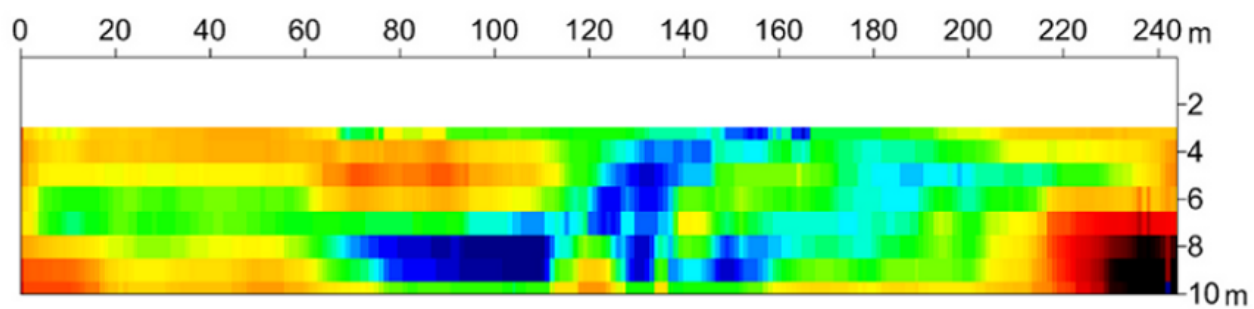

b) 1D interpretated resistivity model

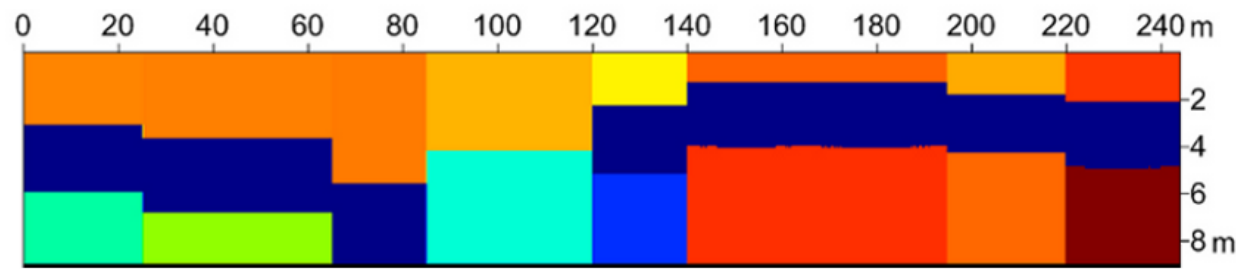

c) Pipe network

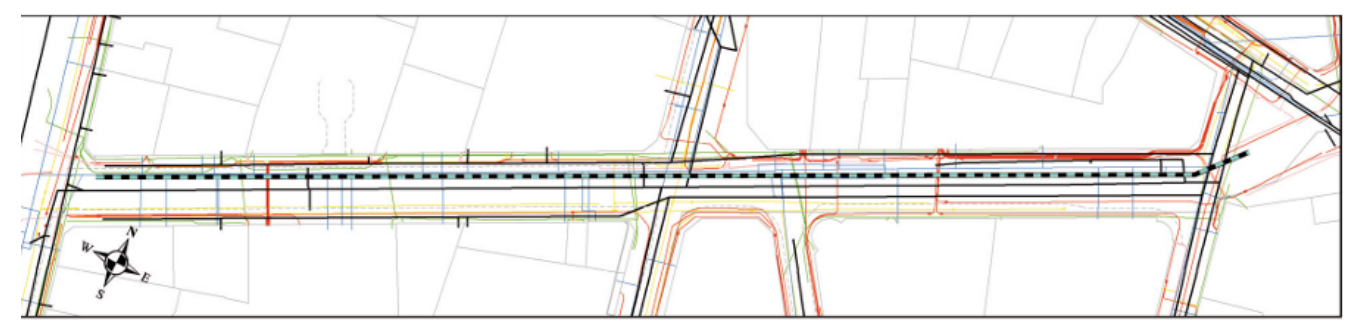

d) 19th century map

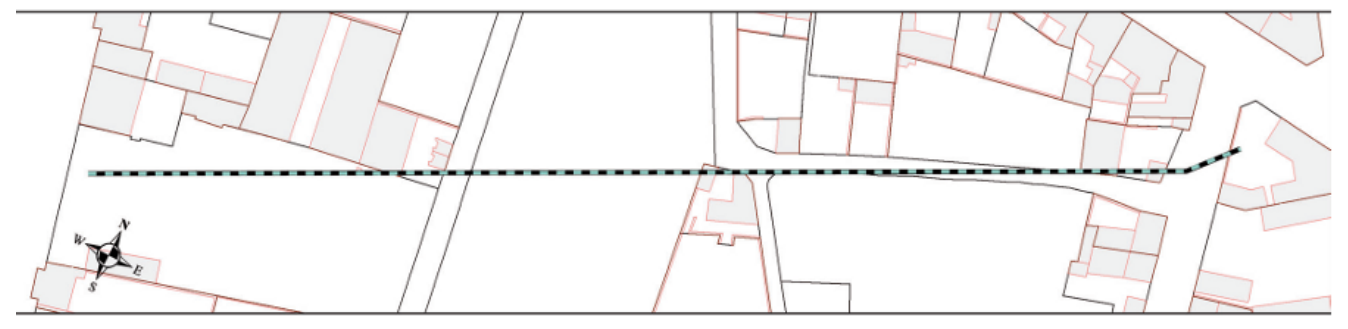

